\title{
Effect of different carotenoid sources and their dietary levels on red porgy (Pagrus pagrus) growth and skin colour
}

\author{
C.T. Kalinowski*, L.E. Robaina, H. Fernández-Palacios, D. Schuchardt, M.S. Izquierdo \\ Grupo de Investigación en Acuicultura, PO Box 56, 35200 Telde, Las Palmas, Canary Islands, Spain
}

Received 21 July 2004; received in revised form 2 November 2004; accepted 2 November 2004

\begin{abstract}
Whereas wild specimens exhibit a red pink silver colour, under captivity red porgy (Pagrus pagrus) skin turns dark grey, being directly associated with lower acceptance by the consumers and lower market value. This study was conducted to evaluate the effect of diet supplementation with two carotenoid sources, at two different concentrations, on growth and skin coloration. Fish of $44 \mathrm{~g}$ mean initial weight were fed the following diets: control (with no added carotenoids), CTX 40 and CTX100 (diets with 40 and $100 \mathrm{mg}$ of synthetic canthaxanthin/kg); SM20 and SM40 (diets with 20 and $40 \mathrm{mg}$ of astaxanthin from shrimp shell meal $/ \mathrm{kg}$ ). Three samplings were carried out in this study, at the beginning and after 75 and 105 days of feeding. At each sampling, individual weight and colour measurements were performed. Colour was evaluated in three different body zones: front lateral (zone I), front dorsal (zone II) and caudal fin (zone III). Growth was not influenced by the inclusion of carotenoids in red porgy diet. Only astaxanthin from shrimp shell meal, particularly at $40 \mathrm{mg} / \mathrm{kg}$ diet, was able to give red porgy skin an overall reddish coloration, suggesting a better utilization of astaxanthin from this source. Shrimp shell meal diets enhanced reddish hue and chroma values, nevertheless hue values at days 75 and 105 did not show a marked difference and chroma attained after 75 days of feeding time tended to be reduced at day 105, suggesting skin colour saturation after a certain feeding time. Carotenoid supplementation did not influence lightness of red porgy skin in the present experiment. From the three evaluated zones, zone I of fish fed SM40 diet presented lower hue, chroma and lightness variation; therefore, it could be proposed as a control zone for future studies. The results of this study suggests that the inclusion of astaxanthin, from shrimp shell meal, in red porgy commercial diets significantly improves skin coloration and markedly enhances the commercial value of this cultured species.
\end{abstract}

(C) 2004 Elsevier B.V. All rights reserved.

Keywords: Carotenoids; Chroma; Growth; Hue; Lightness; Skin

* Corresponding author. Tel.: +34 928 132900; fax: +34 928 132908.

E-mail address: tatianak@iccm.rcanaria.es (C.T. Kalinowski).

\section{Introduction}

Despite the more optimistic projections still forecast a certain increase in European sea bass and gilthead sea bream markets during the next years, 
Table 1

Feed composition and proximate analyses of diets

\begin{tabular}{lcccrr}
\hline & Control & CTX40 & CTX100 & SM20 & SM40 \\
\hline Ingredient & & & & & \\
Fishmeal & 70.9 & 70.9 & 70.9 & 66.3 & 61.7 \\
Shrimp shell meal $^{\mathrm{a}}$ & & & & 8.0 & 16.0 \\
Gelatinized starch & 18.3 & 18.2 & 18.2 & 14.6 & 11.0 \\
Vitamin premix & 2.0 & 2.0 & 2.0 & 2.0 & 2.0 \\
Mineral premix & 2.0 & 2.0 & 2.0 & 2.0 & 2.0 \\
CMC & 0.5 & 0.5 & 0.5 & 0.5 & 0.5 \\
Fish oil & 6.4 & 6.4 & 6.4 & 6.6 & 6.8 \\
Canthaxanthin & & 0.04 & 0.10 & & \\
& & & & & \\
Analysed composition & $\%$ dry & wt.) & & & \\
Crude protein & 51.6 & 50.9 & 52.9 & 52.8 & 53.2 \\
Crude lipids & 13.3 & 15.2 & 13.9 & 14.1 & 14.3 \\
Ash & 10.8 & 9.2 & 10.4 & 12.4 & 13.7 \\
Moisture & 11.0 & 9.7 & 11.8 & 12.3 & 12.0 \\
Astaxanthin (mg/kg) & 9.3 & & & 21.1 & 38.0 \\
Cantaxanthin (mg/kg) & & 38.3 & 100.6 & & \\
\hline
\end{tabular}

a Sopropeche shrimp shell meal, France.

b CAROPHYLL red $10 \%$, F. Hoffman La-Roche Basel, Switzerland.

dependence of most Mediterranean marine fish farms on only two species markedly constrains the further development of aquaculture in this region. Hence, recent studies have being focusing along the last 10 years on diversification of cultured species, many of them belonging to the sparid family (Basurco and Abellán, 1999). Among them, red porgy, a species distributed along the Mediterranean and Atlantic coasts, has been found to be a suitable candidate for aquaculture diversification for a high fillet quality and market price, among other considerations. Previous studies have shown that this species has a good adaptability to culture conditions, spontaneous spawn- ing in captivity and no serious problems of disease or mortalities (Kentouri et al., 1994; Kokokiris, 1998; Schuchardt et al., 2000). These characteristics together with the inability of the wild captures to match the market demands make this species a valuable candidate for finfish mariculture (Manooch and Hassler, 1978; Divanach et al., 1993). However, several authors as well as fish farmers have found that this species loses its natural skin coloration under culture conditions. Thus, whereas wild specimens exhibit a red pink silver colour, under captivity red porgy skin turn dark grey (Kentouri et al., 1995; Stephanou et al., 1995; TECAM, 1999; Cejas et al., 2003). Maintenance of the natural skin pigmentation is of great importance from a commercial point of view, being directly associated with acceptance or rejection by the consumers (Shahidi et al., 1998) and the product market price.

Skin and muscle pigmentation is frequently provided by carotenoid inclusion in fish diets. For instance, to preserve cultured salmon natural muscle coloration diets for salmonid species include different types of carotenoid sources like synthetic astaxanthin and canthaxanthin (Torrissen, 1989; Bjerkeng et al., 1992; Storebakken and No, 1992), carcass meal from red crustacean (Satio and Regier, 1971; Kotic et al., 1974), certain algae or red yeast (Johnson et al., 1980). Carotenoids are also included in commercial diets for red sea beam to maintain good skin coloration (Katayama et al., 1965; Tanaka et al., 1976; Nakazoe et al., 1984). Aside from colouring muscle and skin, there is evidence of the beneficial effects of dietary carotenoid supplementation, such as growth enhancement (Torrissen, 1989; Storebakken

Table 2

Effect of feeding carotenoids supplements on growth and feed utilization parameters after 105 days of experiment $\mathrm{t}^{\mathrm{a}}$

\begin{tabular}{|c|c|c|c|c|c|}
\hline & Control & CTX40 & CTX100 & SM20 & SM40 \\
\hline Initial weight $(\mathrm{g})$ & $43.9 \pm 3.7$ & $43.2 \pm 4.2$ & $45.1 \pm 3.4$ & $44.5 \pm 3.6$ & $43.4 \pm 3.3$ \\
\hline Final weight (g) & $113.3 \pm 13.0$ & $108.8 \pm 15.8$ & $105.7 \pm 12.0$ & $113.2 \pm 12.1$ & $113.6 \pm 14.9$ \\
\hline Feed intake $(\mathrm{g})$ & $1024.2 \pm 95.4$ & $999.9 \pm 13.3$ & $1064.2 \pm 65.6$ & $1079.3 \pm 99.5$ & $1017.9 \pm 41.9$ \\
\hline Growth $^{\mathrm{b}}(\%)$ & $159.0 \pm 17.8$ & $152.3 \pm 13.6$ & $135.9 \pm 9.1$ & $157.0 \pm 8.5$ & $161.8 \pm 14.4$ \\
\hline $\mathrm{SGR}^{\mathrm{c}}$ & $0.91 \pm 0.07$ & $0.88 \pm 0.05$ & $0.82 \pm 0.04$ & $0.90 \pm 0.03$ & $0.91 \pm 0.06$ \\
\hline $\mathrm{FCR}^{\mathrm{d}}$ & $1.2 \pm 0.06$ & $1.3 \pm 0.06$ & $1.5 \pm 0.21$ & $1.3 \pm 0.14$ & $1.2 \pm 0.1$ \\
\hline
\end{tabular}

Values are mean \pm S.D. of three groups per treatment.

${ }^{a}$ No significantly differences $(\mathrm{P}>0.05)$ were observed among treatments means.

${ }^{\mathrm{b}}$ Growth $(\%)=100 \times($ final weight-initial weight $) /$ initial weight.

c SGR: specific growth rate $=100 \times(\ln$ final weight-ln initial weight)/no. days.

${ }^{\mathrm{d}}$ FCR: feed conversion ratio=feed intake $(\mathrm{g}) /$ weight gain $(\mathrm{g})$. 


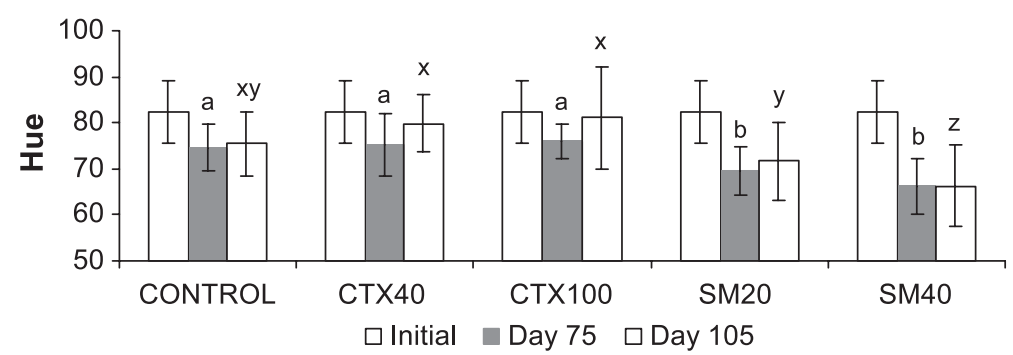

Fig. 1. Hue values $\left({ }^{\circ}\right)$ at days 0,75 and 105 in zone I. Bars represent mean \pm S.D. Means with no letters or with common letters denote no significant differences $(P>0.05)$.

and Goswami, 1996) or improvement of broodstock performance (Verakunpiriya et al., 1997; Watanabe and Vassallo-Agius, 2003).

The aim of the present study was to evaluate the effect of supplementing red porgy diet with synthetic cantaxanthin or astaxanthin (esterified and unesterified) from shrimp shell meal, at two different concentrations, on skin coloration and fish growth.

\section{Materials and methods}

Hatchery reared red porgy, with an initial mean body weight of $44 \mathrm{~g}$, were distributed, indoors, in grey circular fiberglass tanks of 1001 at an initial density of $5.3 \mathrm{~kg} / \mathrm{m}^{3}$. Tanks were continuously provided with natural seawater with at a temperature of $17-19{ }^{\circ} \mathrm{C}$. Dissolved oxygen ranged from 8 to $10 \mathrm{mg} / \mathrm{l}$. Natural light with a photoperiod close to 12-h light/12-h dark was also provided.

Five experimental dry pelleted diets containing $50 \%$ protein and $15 \%$ lipid were evaluated in triplicate groups for a period of 105 days. A control diet with no carotenoid source added; two diets containing, respectively, 40 and $100 \mathrm{mg}$ of synthetic canthaxanthin $/ \mathrm{kg}$, diets CTX40 and CTX100; and another pair containing two levels of shrimp shell meal to provide
20 and $40 \mathrm{mg}$ totally of unesterified and esterified astaxanthin $/ \mathrm{kg}$, diets SM20 and SM40, respectively. Feed was supplied until apparent satiation, three times a day, 6 days a week. The ingredient and biochemical composition of the diets are shown in Table 1. Prior to the beginning of the experiment, fish were fed a commercial gilthead sea bream diet without carotenoids added (Proaqua, Spain).

Biochemical analysis of feed was conducted in triplicate. Moisture, crude protein and ash were determined according to AOAC (1995). Total lipids were extracted by the method of Folch et al. (1957) and carotenoids by that of Barua et al. (1993).

Data on skin colour, whole body weight and total length were recorded in anaesthetised fish, with 2phenoxyethanol, at the beginning, and after 75 and 105 days of feeding. Colour was determined in three zones of the left hand side of the fish: zone I the front lateral, zone II the front dorsal and zone III the caudal fin. Triplicate measurements were taken at each skin zone using a tristimulus colorimeter (Minolta Chroma Meter CR-200, Minolta, Osaka, Japan). The colour parameters were $L^{*}$, lightness, which ranges from 0 for black and 100 for white, $a^{*}$ for red/green chromaticity and $b^{*}$ for yellow and blue chromaticity, in accordance with the recommendations of the International Commission on Illumi-

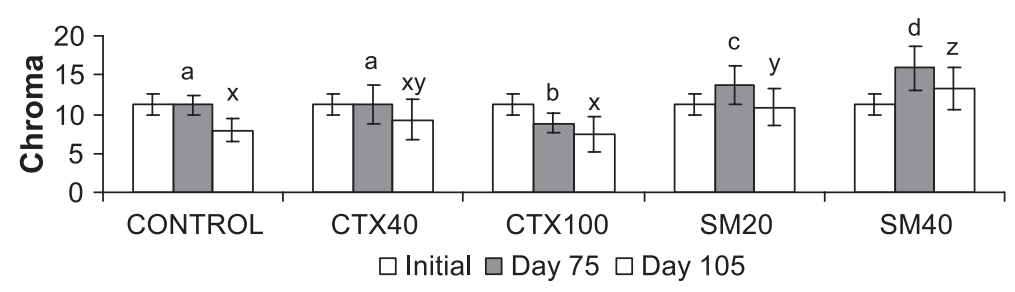

Fig. 2. Chroma values at days 0,75 and 105 in zone I. Bars represent mean \pm S.D. Means with no letters or with common letters denote no significant differences $(P>0.05)$. 


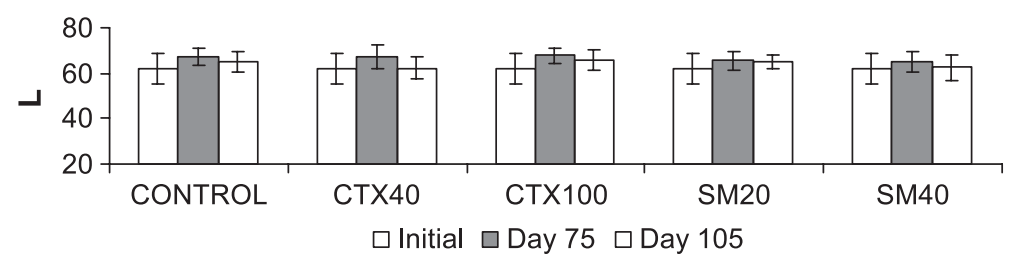

Fig. 3. Lightness values at days 0,75 and 105 in zone I. Bars represent mean \pm S.D. Means with no letters or with common letters denote no significant differences $(P>0.05)$.

nation, CIE (1976). From the $a^{*}$ and $b^{*}$ values, the Hue $\left(H_{a b}\right)$ and chroma $\left(C_{a b}\right)$ values were calculated. Hue, namely the observable colour (e.g. red, blue, yellow), is an angular measurement where $0^{\circ}$ indicates a red hue, $90^{\circ}$ denotes a yellow hue, $180^{\circ}$ green and $270^{\circ}$ blue one, and is calculated by the equation, $H_{a b}=\arctan \left(b^{*} / a^{*}\right)$ (Hunt, 1977). Chroma is an expression of saturation or intensity of the colour attained and is expressed by the equation, $C_{a b}=\left(a^{* 2}+b^{* 2}\right)^{1 / 2}$ (Hunt, 1977).

Means and standard deviations were calculated for all fish for each parameter measured. All data were tested for normality and homogeneity of variance. Differences among groups were determined by oneway ANOVA or non parametric statistics (Kruskal and Wallis). A minimum significance level of $P<0.05$ was used in all tests. To evaluate variability of hue, chroma and lightness, of coloured fish, between each zone, the coefficient of variation was estimated.

\section{Results}

No significant differences were found in growth, SGR and FCR among fish from all dietary treatments (Table 2). Nevertheless, higher growth values were observed in fish feed SM40 diet and lower growth and SGR in fish fed CTX100.
Skin hue values attained in zone I are shown in Fig. 1. Fish feed SM20 and SM40 diets had a significantly $(P<0.05)$ more reddish hue at day 75 , and after 105 days of feeding the tendency of all dietary treatments was to give the skin a yellowish hue, except fish fed SM40 diet that maintained the reddish hue, differing significantly $(P<0.05)$ than the rest. Chroma or saturation degree results (Fig. 2) of fish feed SM40 diet were also significantly $(P<0.05)$ higher than the other fish at both sampling times, despite chroma values being lower in the second one. Skin lightness results (Fig. 3) show no significantly differences among treatments and final values are slightly higher than the initial. Coefficient of variation of hue, chroma and lightness of fish fed SM40 diet, in this zone, was $6.9 \%, 17.9 \%$ and $9.1 \%$, respectively.

In zone II (Fig. 4), skin from fish fed control, CTX40 and CTX100 diets showed significantly $(P<0.05)$ higher hue values giving this zone a yellowish hue. Shrimp shell meal diets did not alter hue values in this zone. Although at the end of the experiment, chroma (Fig. 5) values were reduced in zone II of all fish, that of fish fed SM40 diet was significantly $(P<0.05)$ higher than the rest. Similarly, lightness tended to decrease along the experiment (Fig. 6). Hue, chroma and lightness of fish fed SM40 diet presented coefficient of variation of $25.1 \%$, $42.4 \%$ and $13.1 \%$, respectively.

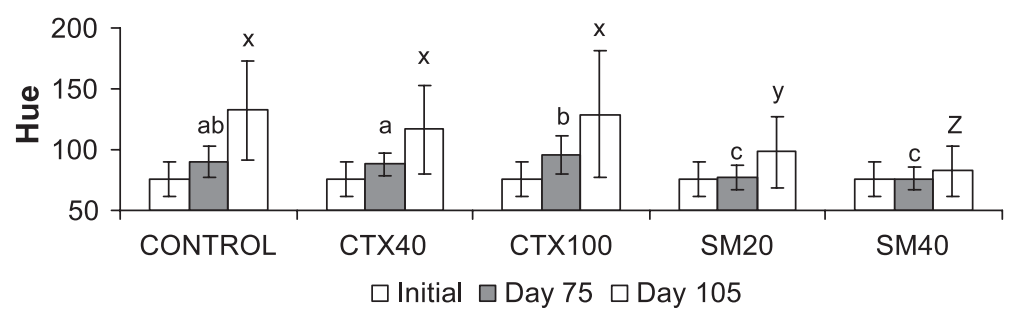

Fig. 4. Hue values $\left(^{\circ}\right)$ at days 0,75 and 105 in zone II. Bars represent mean \pm S.D. Means with no letters or with common letters denote no significant differences $(P>0.05)$. 


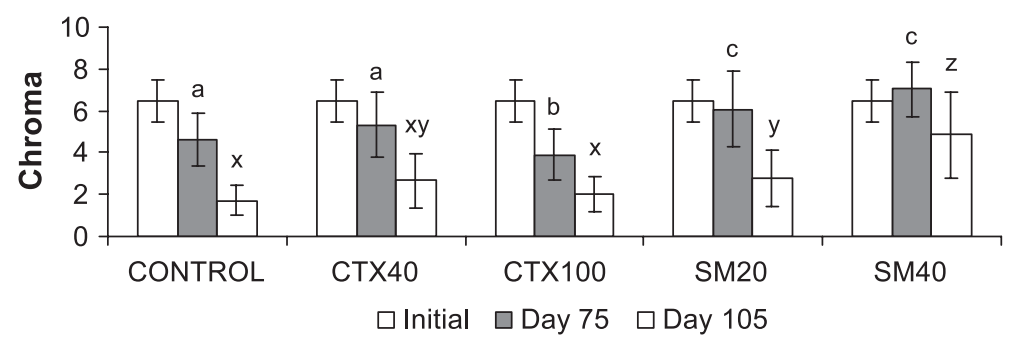

Fig. 5. Chroma values at days 0, 75 and 105 in zone II. Bars represent mean \pm S.D. Means with no letters or with common letters denote no significant differences $(P>0.05)$.

Hue results in zone III are shown in Fig. 7. Fish feed SM20 and SM40 diets were significantly $(P<0.05)$ more reddish throughout the experiment; although, redness tended to decrease at day 105 in fish fed both diets. In zone III, chroma values (Fig. 8) for SM20 and SM40 fish skin were significantly $(P<0.05)$ higher than the rest even at the final sampling when all values tended, once again, to be lower. Lightness results showed no statistical differences among treatments (Fig. 9). Coefficient of variation of hue, chroma and lightness of SM40 diet fish was $7.4 \%, 27.6 \%$ and $11.5 \%$, respectively.

\section{Discussion}

Carotenoids are known to have a positive role in the intermediary metabolism of fish (Tacon, 1981; Segner et al., 1989) that could enhance nutrient utilisation and may ultimately result in improved growth (Amar et al., 2001). In the present study, fish feed a carotenoid source did not differ from control fish in growth and FCR. These results are in accordance with another study carried out with red porgy juveniles fed krill meal, for 75 days, as a source of astaxanthin (Chebbaki, 2001) and agree well with that of Gomes et al. (2002) who did not find growth or feed efficiency enhancement when gilthead sea bream were fed different carotenoids for 9 weeks. Also, a study with rainbow trout (Nickell and Bomage, 1998) found no significant differences. Nevertheless, this study with rainbow trout, found that fish fed an astaxanthin supplemented diet from 6.5 and 25.5 until $400 \mathrm{~g}$ exhibited higher wet weight than fish fed astaxanthin from 120.5 up to $400 \mathrm{~g}$; these results suggest supplementing for longer periods are needed to evaluate a possible role on growth.

From the two carotenoid sources and dietary levels used in the present study, only $40 \mathrm{mg}$ of astaxanthin from shrimp shell meal/kg diet, which is mainly in a esterified form, was able to give red porgy an overall reddish coloration, suggesting a better utilization of the esterified astaxanthin by this species. Astaxanthin esters were also more efficiently utilized for deposition and coloration of the skin than free astaxanthin in red sea bream (Nakazoe, 1984; Ito, 1986; Lorenz, 1998). In other species such as Australian snapper (Booth et al., 2004), both unesterified or esterified forms of astaxanthin provide similar contents of astaxanthin in the skin. Also, in gilthead sea bream synthetic astaxanthin and cantaxanthin or pigments

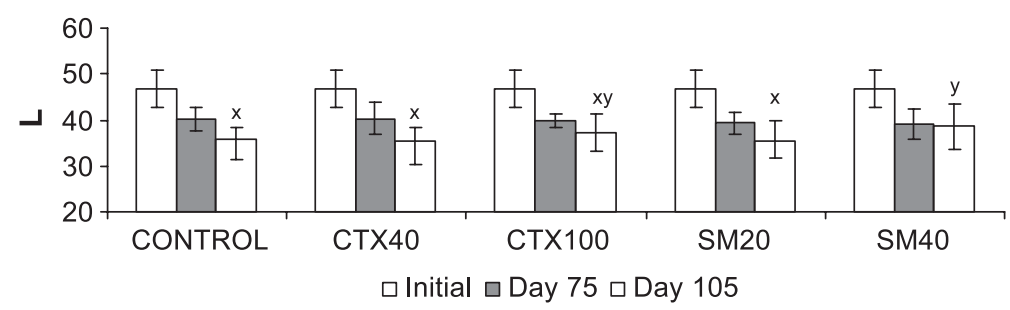

Fig. 6. Lightness values at days 0,75 and 105 in zone II. Bars represent mean \pm S.D. Means with no letters or with common letters denote no significant differences $(P>0.05)$. 


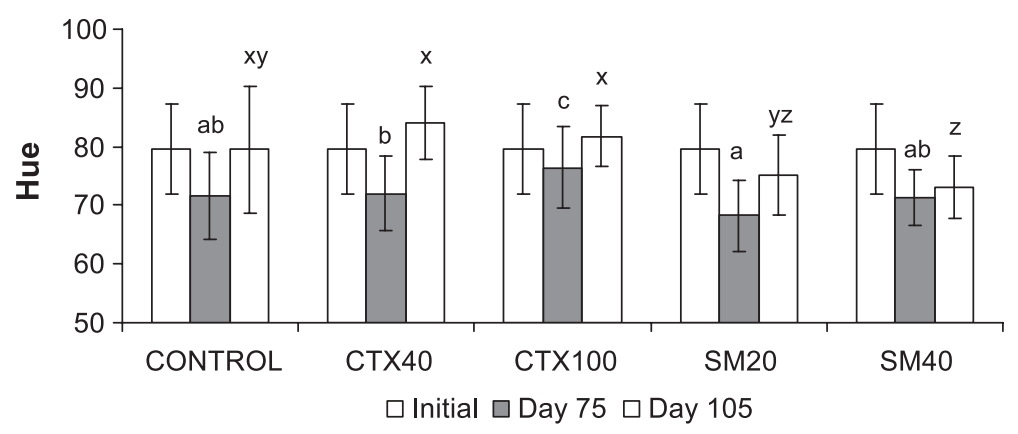

Fig. 7. Hue values $\left(^{\circ}\right)$ at days 0,75 and 105 in zone III. Bars represent mean \pm S.D. Means with no letters or with common letters denote no significant differences $(P>0.05)$.

from algae were efficiently absorbed, as shown in plasma carotenoid composition (Gomes et al., 2002). Both astaxanthin and canthaxanthin, either alone or in combination, have being efficiently used for muscle pigmentation in salmonids (Bjerkeng, 2000). However, astaxanthin in a esterified form is less efficiently used by these species (Torrissen and Braekken, 1979; Schiedt et al., 1985).

Canthaxanthin supplemented diets affected skin coloration giving a yellowish hue and atypical chroma values, since increase dietary carotenoids usually raises chroma values whereas fish fed CTX100 diet attained lower chroma values than fish fed CTX40 diet. Red sea bream, fed $\beta$-carotene or canthaxanthin, showed a decrease in the carotenoid level in the integuments (Lorenz, 1998). Decrease in deposition can be explained by a limitation in the rate of absorption (Torrissen et al., 1990). In rainbow trout, it is stated that astaxanthin is a better pigment source than canthaxanthin; also, it has been found to be better absorbed through the digestive tract and a preferred deposition of astaxanthin in the flesh (Torrissen, 1989).
There is an uneven distribution of colour in red porgy skin, the front lateral zone exhibiting a more reddish hue and higher chroma values, followed by the caudal and finally dorsal zone. These results suggested a progressive deposition of astaxanthin in these three body zones, since coloration and the concentration of carotenoids are significantly related (Bjerkeng, 2000). Uneven colour distribution was also found in salmonids muscle, where a longitudinal variation in carotenoid content and red colour was found, with more astaxanthin deposited in the caudal than in the anterior part (Bjerkeng, 2000). A part from an uneven distribution, the variability of hue, chroma and lightness of pigmented fish from SM40 diet was lower in zone I than in the other two zones.

In the present study, dietary pigment that enhanced reddish hue and chroma values tended to be reduced after 105 days of feeding. This behaviour of hue and chroma suggest a certain skin colour saturation. In agreement, an apparent colour saturation point was found in red sea bream fed $100 \mathrm{mg}$ free astaxanthin $/ \mathrm{kg}$ diet for a month, with no further increase afterwards

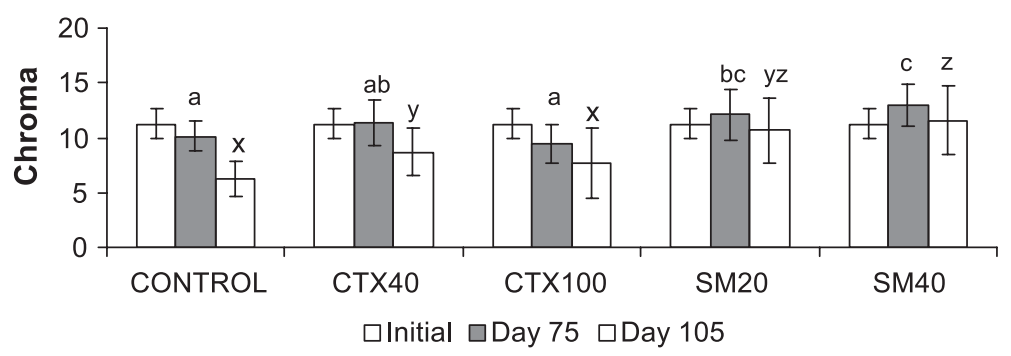

Fig. 8. Chroma values at days 0, 75 and 105 in zone III. Bars represent mean \pm S.D. Means with no letters or with common letters denote no significant differences $(P>0.05)$. 


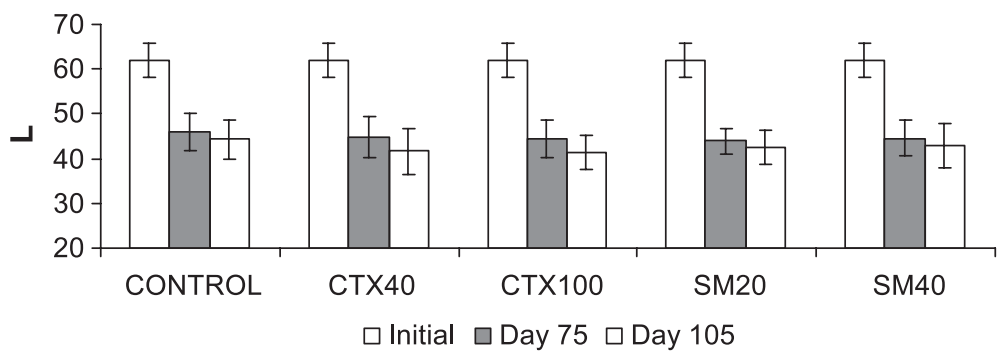

Fig. 9. Lightness values at days 0,75 and 105 in zone III. Bars represent mean \pm S.D. Means with no letters or with common letters denote no significant differences $(P>0.05)$.

(Ito et al., 1986), whereas when fish were fed astaxanthin esters maximum astaxanthin contents were found after 2 months of feeding. This saturation plateau found in fish fed carotenoids seems to depend on genetical factors (Torrissen and Naevdal, 1984) nutritional (Torrissen, 1985) and biological factors such as fish size and specie.

Carotenoid supplementation did not influence lightness of red porgy skin in the present experiment. Skin pigmentation in vertebrates is modified by hormonal stimulation, background colour and the illumination (Sugimoto, 1993; Duray et al., 1996; Crook, 1997; Healey, 1999; Papoutsoglou et al., 2000; Rotllant et al., 2003). For instance, in Australian red snapper, skin darkness seems to be a response to the proximity of sea cages to the surface of the water and the subsequent effect of sunlight exposure on melanin concentration in the skin (Booth et al., 2004). Handling stress and sacrificed methods are also among factors that negatively influence fish skin lightness (Qun Lin et al., 1998).

The present study suggested that Pagrus pagrus skin pigmentation can be modified from a dark grey to a red pink silver colour, supplementing the diet with $40 \mathrm{mg}$ of astaxanthin $/ \mathrm{kg}$ diet contained in shrimp shell meal. From the three evaluated zones, the front lateral zone seems accumulate more astaxanthin, showing a more reddish coloration than the other two zones and less variability; in further studies, this zone can be used as a control for evaluating the overall redness attained in this species. Nevertheless, since diet is not the only parameter that modifies skin pigmentation, its relation with environmental factors and aquaculture related stressors should be considered for the adequate coloration of red porgy.

\section{Acknowledgements}

This study was supported by an EU project COLORED Q5RS-2000-31629 and Agencia Española de Cooperación Internacional (AECI).

\section{References}

Amar, E.C., Kiron, V., Satoh, S., Watanabe, T., 2001. Influence of various dietary synthetic carotenoids on bio-defence mechanisms in rainbow trout, Oncorhynchus mykiss (Walbaum). Aquac. Res. 32 (Suppl. 1), 162-163.

AOAC, 1995. Official Methods of Analysis of the Association of Analytical Chemistry. Washington, DC. 1018 pp.

Barua, A.B., Kostic, D., Olson, J.A., 1993. New simplified procedures for the extraction and simultaneous high performance liquid chromatographic analysis of retinol, tocopherols, and carotenoids in human serum. J. Chromatogr. 617, 257-264.

Basurco, B., Abellán, E., 1999. Finfish species diversification in the context of the Mediterranean marine fish farming development. Options Mediterr., Ser. B: Etudes Rech. 24, 9-25.

Bjerkeng, B., 2000. Carotenoid pigmentation of salmonid fishesrecent progress. In: Cruz-Suárez, L.E., Rique-Marie, D., TapiaSalazar, M., Overa-Novoa, M.A., y Civera-Cerecedo, R. (Eds.), Avances en Nutrición Acuícola V. Memorias del V Simposium Internacional de Nutrición Acuícola 19-22 Noviembre, 2000. Mérida, Yucatán.

Bjerkeng, B., Storebakken, T., Liaaen-Jensen, S., 1992. Pigmentation of rainbow trout from start feeding to sexual maturation. Aquaculture 108, 333-346.

Booth, M., Warner-Smith, R., Allan, G., Glencross, B., 2004. Effects of dietary astaxanthin source and light manipulation on the skin colour of Australian snapper Pagrus auratus (Bloch and Schneider, 1801). Aquac. Res. 35, 458-464.

Cejas, J., Almansa, E., Tejera, N., Jerez, S., Bolaños, A., Lorenzo, A., 2003. Effect of dietary supplementation with shrimp on skin pigmentation and lipid composition of red porgy (Pagrus pagrus) alevins. Aquaculture 218, 457-469.

Chebbaki, K., 2001. Efecto de la nutrición sobre la coloración de la piel y la calidad del filete en bocinegro, Pagrus pagrus. Master 
Thesis. II International Master in Aquaculture, Universidad de las Palmas de Gran Canaria, Spain, 93 pp.

CIE, 1976. Official Recommendations on Uniform Colour Space, Colour Difference Equations and Metric Colour Terms. Suppl. No. 2 to CIE Publication No.15, Colorimetry. Commission International de l'Eclairage, Paris.

Crook, A.C., 1997. Colour patterns in a coral reef fish-is background complexity important? J. Exp. Mar. Biol. Ecol. $217,237-252$.

Divanach, P., Kentouri, M., Charalambakis, G., Pouget, F., Sterioti, A., 1993. Comparison of growth performance of six Mediterranean fish species reared under intensive conditions in Crete (Greece), in raceways with the use of self-feeders. In: Barnabé, G., Kestemont, P. (Eds.), Production, Environment and Quality. Bordeaux Aquaculture 92, Special Publication, vol. 1. European Aquaculture Society, Ghent, pp. 285-297.

Duray, M.N., Estudillo, C.B., Alpasan, L.G., 1996. The effect of background colour and rotifer density on rotifer intake, growth and survival of grouper. (Epinephelus suillus) larvae. Aquaculture 146, 217-224.

Folch, J., Lees, M.S., Stanley, G.H.S., 1957. A simple method for the isolation and purification of total lipids from animal tissue. J. Biol. Chem. 226, 479-509.

Gomes, E., Dias, J., Silva, P., Valente, L., Empis, J., Gouveia, J.B., Young, A., 2002. Utilization of natural and synthetic sources of carotenoids in the skin pigmentation of gilthead sebream (Sparus aurata). Eur. Food Res. Technol. 214, 287-293.

Healey, E.G., 1999. The skin pattern of young plaice and its rapid modification in response to graded changes in background tint and pattern. J. Fish Biol. 55, 937-971.

Hunt, R.W.G., 1977. The specification of colour appearance: I. Concepts and terms. Color Res. Appl. 2, 55-68.

Ito, Y., Kamata, T., Sameshima, M., 1986. Studies on the improvement of body colour of red sea bream Pagrus major by astaxanthin and astaxanthin dipalmitate. Suisan Zoshoku 34, $77-80$.

Johnson, E.A., Villa, T.G., Lewis, M., 1980. Phaffia rhodozyna as an astaxanthin source in salmonids diets. Aquaculture 20, $123-134$.

Katayama, T., Ikeda, N., Harada, K., 1965. Carotenoids in sea breams, Chrysophrys major and schlegel. Bull. Jpn. Soc. Sci. Fish. 31, 947-952.

Kentouri, M., O’Neil, D., Divanach, P., Charalambakis, G., 1994. A study of the quantitative water requirements of red porgies Pagrus pagrus L. (Pisces: Sparidae), during early on growing under self feeding conditions. Aquac. Fish. Manage. $25,741-752$.

Kentouri, M., Pavlidis, M., Papandroulakis, N., Divanach, P., 1995. Culture of red porgy, Pagrus pagrus, in Crete. Present knowledge, problems and perspectives. Cah. Options Mediterr. 16, $65-78$.

Kokokiris, L., 1998. The reproductive cycle and hermaphrodite pattern in Pagrus pagrus. PhD thesis, University of Crete, pp. 219.

Kotic, I.V., Tolokonnikov, G.Y., Dubrovin, V., 1974. The effect of krill meal additions to feeds on muscle pigmentation in the rainbow trout, Salmo gairdneri. J. Ichthyol. 19, 114-123.
Lorenz, T.R., 1998. A review of astaxanthin as a carotenoid and vitamin source for sea bream. Naturerose Technical Bulletin, vol. 052. Cyanotech, Hawaii, USA.

Manooch, C.S., Hassler, W.W., 1978. Synopsis of biological data on the red porgy Pagrus pagrus (Linnaeus). NOAA Technical Report NMFS Circular 412, 18 pp.

Nakazoe, J., Ishii, S., Kamimoto, H., Takeuchi, M., 1984. Effects of supplemental carotenoid pigments on the carotenoid accumulation in young red sea bream Chrysophrys major. Bull. Tokai Reg. Fish. Res. Lab. 113, 29-41.

Nickell, D.C., Bomage, N.R., 1998. The effect of timing and duration of feeding astaxanthin on the development and variation of fillet colour and efficiency of pigmentation in rainbow trout (Oncorhynchus mykiss). Aquaculture 169, $233-246$.

Papoutsoglou, S.E., Mylonakis, G., Miliou, H., Karakatsouli, N.P., Chadio, S., 2000. Effects of background colour on growth performances and physiological responses of scaled carp (Cyprinus carpio L.) reared in a close circulating system. Aquac. Eng. 22, 300-318.

Qun Lin, M., Ushio, H., Ohshima, T., Yamanaka, H., Koizumi, C., 1998. Skin color control of the red sea bream (Pagrus major). Lebensm.-Wiss. Technol. 31, 27-32.

Rotllant, J., Tort, L., Montero, D., Pavlidis, M., Martinez, M., Wenderlaar Bonga, S.E., Balm, P.H.M., 2003. Background colour influence on the stress response in cultured red porgy Pagrus pagrus. Aquaculture 223, 129-139.

Satio, A., Regier, L.W., 1971. Pigmentation on brook trout (Salvelinus fontalis) by feeding dry crustacean waste. J. Fish. Res. Board Can. 26, 357-360.

Schiedt, K., Leuenberger, F.J., Vecchi, M., Glinz, E., 1985. Absorption, retention and metabolic transformation of carotenoids in rainbow trout, salmon and chicken. Pure Appl. Chem. 57, 685-692.

Schuchardt, D., Vergara, J.M., Robaina, L., Montero, D., 2000. The effects of varying dietary protein and lipid levels on growth, feed efficiency, protein utilization and body composition of red porgy fingelings. The Ninth Intern. Symp. on Nutrition and Feeding in Fish 2000, Miyasaki, JAPAN, pp. 91.

Segner, H., Arend, P., Von Poeppinghaussen, K., Schmidt, H., 1989. The effect of feeding astaxanthin to Oreochromis niloticus and Colisa labiosa on the histology of the liver. Aquaculture 79, $381-390$.

Shahidi, F., Metusalach, A., Brown, J.A., 1998. Carotenoid pigments in seafoods and aquaculture. Crit. Rev. Food Sci. Nutr. 38, 1-67.

Stephanou, D., Georgiou, G., Shourkri, E., 1995. Reproduction and larval rearing of the common seabream (Pagrus pagrus), an experimental culture. Cah. Options Mediterr. 16, 79-87.

Storebakken, T., Goswami, U.C., 1996. Plasma carotenoid concentration indicates the availability of dietary astaxanthin for Atlantic salmon, Salmo salar. Aquaculture 146, 147-153.

Storebakken, T., No, H.K., 1992. Pigmentation of rainbow trout. Aquaculture 100, 209-229.

Sugimoto, M., 1993. Morphological colour changes in the medaka Oryzias latipes, after prolonged background adaptation: I. Changes in the population and morphology of the melanophores. Comp. Biochem. Physiol., A 104, 513-518. 
Tacon, A.G.J., 1981. Speculative review of possible carotenoid function in fish. Prog. Fish-Cult. 43, 205-208.

Tanaka, Y., Katayama, K.L., Simpson, K., Chichester, C.O., 1976. The carotenoids in marine red fish and the metabolism of the carotenoids in sea bream, Chrysophrys major Temminch and Schegel. Bull. Jpn. Soc. Sci. Fish. 42, 1177-1182.

TECAM, Survey on Mediterranean Marine Finfish Species Diversification, 1999. Marine finfish species diversification: current situation and prospects in Mediterranean aquaculture. Options Mediterr., Ser. B: Etudes Rech. 24169 pp.

Torrissen, O.J., 1985. Pigmentation of salmonids: factors affecting carotenoid deposition in rainbow trout (Salmo gairdneri). Aquaculture 46, $133-142$.

Torrissen, O.J., 1989. Pigmentation of salmonids: interaction of astaxanthin and cantaxanthin on pigment deposition in rainbow trout. Aquaculture 79, 363-374.

Torrissen, O.J., Braekken, O.R., 1979. The utilisation of astaxanthin forms by rainbow trout (Salmo gairdneri). In: Halver, J.E.,
Tiews, K. (Eds.), Finfish Nutrition and Fishfeed Technology, vol. II. Heenemann, Berlin, pp. 377-382.

Torrissen, O.J., Naevdal, G., 1984. Pigmentation of salmonidsgenetical variation in carotenoid deposition in rainbow trout. Aquaculture 38, 59-66.

Torrissen, O.J., Hardy, R.W., Shearer, K.D., Scott, T.M., Stone, F.E., 1990. Effects of dietary canthaxanthin level and lipid level on apparent digestibility coefficients for canthaxanthin in rainbow trout (Oncorhynchus mykiss). Aquaculture 88, 351-362.

Verakunpiriya, V., Watanabe, K., Mushiake, K., Kawano, K., Kobayashi, T., Hasegawa, I., Kiron, V., Satoh, S., Watanabe, T., 1997. Effect of krill meal supplementation in soft dry pellets on spawning and quality of egg of yellowtail. Fish. Sci. 63, $433-439$.

Watanabe, T., Vassallo-Agius, R., 2003. Broodstock nutrition research on marine finfish in Japan. Aquaculture 227, 35-61. 